\title{
Operação Ótima das Chaves de Interconexão em uma Rede de Distribuição Radial.
}

\section{Lucas Zenichi Terada*, Marcos Julio Rider Flores .}

\begin{abstract}
Resumo
A reconfiguração das redes de distribuição de energia elétrica determina o estado de operação das chaves disponíveis na rede com o objetivo de minimizar os custos operativos do sistema de distribuição. Adicionalmente, a topologia final da reconfiguração deve garantir que as resitrições operacionais do sistema sejam respeitadas, isto é, que os limites de magnitude de tensão dos nós, os limites de magnitude de correntes pelos ramos, as capacidades dos alimentadores se mantenham dentro das faixas de segurança estabelecidos e a operação radial da rede de distribuição.
\end{abstract}

\section{Palavras-chave:}

Eficiência energética, engenharia elétrica, otimização, reconfiguração, redução de custo.

\section{Introdução}

Os sistemas de distribuição de energia elétrica (SDEE) são planejados como redes de malhas interconectadas. Com a finalidade de operar de forma mais eficiente de modo a coordenar a proteção do sistema mais facilmente e reduzir a corrente de curto circuito, o SDEE opera com uma topologia radial${ }^{2}$.

Os SDEE devem operar de forma a respeitar tanto as restrições de carga quanto as restrições operacionais. Dado que o sistema está operando em regime permanente ${ }^{3}$ é interessante operá-lo em estado de mínimas perdas. Para isso reconfigura-se o sistema de distribuição de modo a reduzir as perdas ôhmicas ao longo da rede.

O problema de reconfiguração do sistema de distribuição é um problema de planejamento da operação das chaves alocadas ao longo dos alimentadores e consiste na abertura e/ou fechamento das chaves com o objetivo de melhorar um índice de desempenho.

A reconfiguração ótima é uma importante ferramenta para aumentar a confiabilidade de um SDEE, especialmente quando a automação avançada e tecnologias de redes inteligentes (smartgrids) tornam-se mais importantes e mais acessíveis concessionarias de distribuição.

\section{Resultados e Discussão}

O desenvolvimento do projeto foi baseado em um problema de planejamento cuja função objetivo é a minimização da somatória de perdas ôhmicas em todo o conjunto de ramos, de modo que obedeça às restrições físicas e operativas da rede de distribuição.

Através de uma linguagem de modelagem matemática, implementou-se o problema e o submeteu a um programa solucionador cujo objetivo é alterar os estados das chaves presentes no sistema. Um exemplo de reconfiguração é dada através da figura 1, na qual alterou-se os estados de duas chaves modificando a topologia da rede.

Em um primeiro momento, com uma modelagem não linear, encontrou-se, para um sistema teórico de 45 nós com chaves já disposta na rede de distribuição, uma redução de $45,5 \%$ de perdas de potência ativa. Além disso o algotítmo, dado suas restrições, manteve os níveis de tensões dentro dos limites impostos pela ANEL para uma rede de média tensão ${ }^{1}$.

Por fim, dado a dificuldade em utilizar algorítmos não lineares, aplicou-se uma técnica de linearização nas restrições que descrevem o fluxo de potência aparente nos ramos da rede. Embora o número de variáveis aumente com a implementação de técnicas de linearização, sabe-se que um problema de programação linear é muito mais rápido e confiável que um problema de programação não linear.

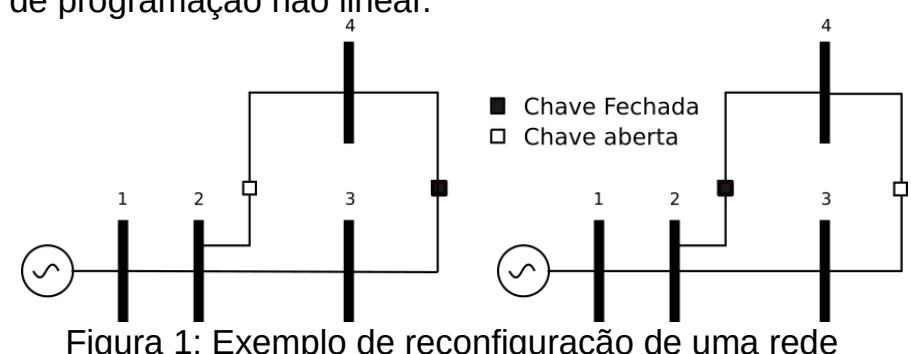

Figura 1: Exemplo de reconfiguração de uma rede teórica de distribuição radial.

\section{Conclusão}

Através desse trabalho é notável como o planejamento de uma rede de média tensão com característica radial traz benefícios econômicos a longo prazo, de modo a tornar discutível a criação de chaves interconectoras ao longo da rede de distribuição com a finalidade de, alternado seus estados, minimizar as perdas da rede e balancear os níveis de tensões.

\section{Agradecimentos}

Meus agradecimentos à Fundação de Amparo à Pesquisa do Estado de São Paulo pelo incentivo a pesquisa.

\footnotetext{
1 Agência Nacional de Energia Elétrica. Módulo 8- Qualidade da Energia Elétrica Revisão Motivo da Revisão Instrumento de aprovação pela ANEEL [Relatório técnico]. Brazil; 2017.

${ }^{2}$ Romais, Rodrigo. Reconfiguração ótima dos sistemas de distribuição de energia elétrica usando uma formulação cônica de segunda ordem inteira mista. 2014. 100 f. Dissertação (mestrado) - Universidade Estadual Paulista Júlio de Mesquita Filho, Faculdade de Engenharia de Ilha Solteira, 2014.

${ }^{3}$ Shirmohammadi, D.; Hong, H. W.; Semlyen, A.; \& Luo, G. X. (1988). A compensation-based power flow method for weakly meshed distribution and transmission networks. IEEE Transactions on power systems, 3(2), 753-762.
} 